\title{
AN AGGREGATE TRANSPORT DEMAND MODEL FOR IMPORT AND EXPORT FLOW SIMULATION
}

\author{
Agostino Nuzzolo, Umberto Crisalli, Antonio Comi \\ Dept of Enterprise Engineering, University of Rome 'Tor Vergata', \\ Via del Politecnico 1, 00133 Rome, Italy \\ Submitted 6 December 2012; accepted 23 February 2013; \\ first published online 25 October 2013
}

\begin{abstract}
This paper presents a system of models for the estimation of international (import/export) freight flows through a partial share approach. It allows us to simulate attraction, production, distribution and modal split for the estimation of modal Origin-Destination matrices in quantities. Aiming at predicting long term effects for strategic planning, the modelling system has been specified through easy-to-capture variables represented by level-of-service attributes and aggregate socio-economic variables. The calibration was carried out by using a set of available data in Italy that allowed us to consider import/export flows for different freight types given by the aggregation of classes provided by European NST/R classifications.
\end{abstract}

Keywords: import/export; international freight transport demand; freight demand elasticity; mode choice; distribution model.

\section{Introduction}

Latest years have been characterised by a stronger contraction of commercial flows compared to those occurred after the Second World War. One of the main reasons is due to the decrease of international commerce followed by the reduction of goods production. The contraction of goods with high added value (which represents the main part of world Gross Domestic Product GDP) influenced the intermediate goods in all the industrialised countries around the world. Table 1 reports the distribution of commercial freight flows around the world (ICE 2009, 2012). East Asia had an increasing of import and export shares in 2012 with respect to the other macro-areas. In fact, after the strong period of crisis, from 2010 the international exchanges should grow under the push of emerging countries. It has been estimated that in the next years the level of exchanges should reach the pre-crisis values. From the analysis of data reported in Table 1, we can see that European countries reduced their import and export. In spite of this, the European countries remain the leading import and export area in the world.

In this context, the stakeholders have to be supported with adequate models and tools in order to forecast the demand and to assess network performance that reflects on shipping efficiency. This is a crucial point if, besides transport issues, we also consider the opportunity provided by logistic services like groupage/degroupage ones (i.e. components manufactured in different locations that could be transported to a single location for assembly before being shipped again to their final destination).

Freight transportation is usually measured and described by either commodity or vehicle movements. Freight demand is derived from the socio-economic system in which raw materials, intermediate inputs and finished products are needed at specific locations and precise times. Therefore, the primary focus on freight transport demand modelling should be on commodity movements since vehicle movements are triggered by the need of moving commodity.

At international level, the aim of this class of models is to estimate goods movement between different countries. International goods movement has been characterised by an explosive growth in the last decade due to the East locations of operations of multinational firms as a mean to take advantage of competitive prices for both materials and labour. 
Table 1. Distribution of import/export flows (share respect to current prices)

\begin{tabular}{|c|c|c|c|c|c|}
\hline \multirow{2}{*}{ Geographic Area } & \multicolumn{5}{|c|}{ Import } \\
\hline & 2007 & 2008 & 2009 & 2010 & 2011 \\
\hline European Union & 38.2 & 36.7 & 38.1 & 35.6 & 34.7 \\
\hline Euro Zone & 26.0 & 26.8 & 27.8 & 25.6 & 25.1 \\
\hline Non-European Union & 6.3 & 7.0 & 3.4 & 3.2 & 3.4 \\
\hline Africa & 3.1 & 3.5 & 3.3 & 3.1 & 3.0 \\
\hline North America & 13.2 & 12.6 & 17.5 & 17.8 & 17.2 \\
\hline $\begin{array}{l}\text { Central and South } \\
\text { America }\end{array}$ & 3.6 & 3.7 & 3.6 & 3.9 & 4.0 \\
\hline Middle East & 5.5 & 6.4 & 4.1 & 3.8 & 3.7 \\
\hline Central Asia & 1.8 & 2.1 & 2.1 & 2.0 & 2.4 \\
\hline East Asia & 27.0 & 26.5 & 26.2 & 27.9 & 28.5 \\
\hline Oceania and other & 1.3 & 1.5 & 1.7 & 2.7 & 3.1 \\
\hline World & 100.0 & 100.0 & 100.0 & 100.0 & 100.0 \\
\hline \multirow{2}{*}{ Geographic Area } & \multicolumn{5}{|c|}{ Export } \\
\hline & 2007 & 2008 & 2009 & 2010 & 2011 \\
\hline European Union & 39.2 & 38.1 & 37.9 & 34.8 & 33.9 \\
\hline Euro Zone & 26.0 & 25.4 & 29.0 & 26.4 & 25.7 \\
\hline Non-European Union & 5.6 & 6.0 & 3.6 & 3.3 & 3.2 \\
\hline Africa & 2.6 & 2.9 & 3.3 & 3.4 & 3.4 \\
\hline North America & 18.9 & 17.6 & 13.2 & 13.3 & 12.8 \\
\hline $\begin{array}{l}\text { Central and South } \\
\text { America }\end{array}$ & 3.2 & 3.6 & 3.9 & 4.0 & 4.2 \\
\hline Middle East & 3.3 & 3.6 & 5.8 & 6.0 & 6.9 \\
\hline Central Asia & 2.4 & 2.8 & 3.1 & 3.5 & 3.8 \\
\hline East Asia & 23.2 & 23.7 & 26.4 & 28.2 & 27.3 \\
\hline Oceania and other & 1.6 & 1.7 & 2.8 & 3.5 & 4.5 \\
\hline World & 100.0 & 100.0 & 100.0 & 100.0 & 100.0 \\
\hline
\end{tabular}

Source: ICE $(2009,2012)$

Demand models play a key role for transport planning. Public agencies need to forecast future transport requirements for both people and commodities in order to provide infrastructures and services that allow such a movement. The private sector needs to forecast demand for transport services to anticipate, among others, future financial requirements, equipment acquisition and labour requirements.

Models developed to simulate the international freight flows can be classified in aggregate or disaggregate according to used variables. Aggregate variables regard, for example, data of all companies of a precise category and/or economic sector; disaggregate variables regard, for example, data on individual companies or individual shipments (Ben-Akiva et al. 2008). Disaggregate models have several advantages over aggregate. Disaggregate models can be based on a foundation in behavioural theory; they can include more detailed policy-relevant variables and do not suffer from the aggregation biases of aggregate models. Nevertheless, there are many reasons to explain why some of the components of a model system are modelled in an aggregate way, for example data availability (Ben-Akiva, De Jong 2008). A further classification of demand models refers to the model structure between partial share models (multi-step models) and joint/direct models. Partial share models consider a progressive split of the whole process into different steps (e.g. generation, distribution and modal split) within which each sub-model of the sequence is treated/solved independently from the others. Joint/direct models differ from the previous ones because the whole process is simultaneously approached (all in one) as, for example, it is described in McFadden et al. (1986) and Abdelwahab and Sargious (1991). Given the difficulty of collecting disaggregate data, which mainly refer to information carried out by direct interviews to firms, the disaggregate models mainly focus on specific aspects of the transport process such as mode or path choices.

Freight transport models are used for different purposes, including (Ben-Akiva, De Jong 2008):

- forecasting transport demand in the medium to long run under various scenarios;

- testing transport policy measures, such as road user charging;

- predicting the impacts on traffic of the prevision of new infrastructure.

The focus of this paper is on the transport demand models to simulate international flows. The literature reports several models developed to support the assessment of various scenarios, but most of them have been developed to be used at national scale. They consider the import/export flows as exogenous data and they do not take into account how variations of import/export shares impact on the national economies. Furthermore, most developed models for the international freight transport refer to shipping and containerised flows (Thill, Lim 2010; Nuzzolo et al. 2013).

In relation to models developed for international freight transport and logistics, among papers which report reviews and possible model classifications we can refer to De Jong et al. (2004, 2013), Chow et al. (2010).

De Jong et al. (2004) proposed a literature review on freight transport models, focusing on models developed since the nineties for forecasting, policy simulation and project evaluation at the national and international level. They mainly reviewed the European studies and, for what concerns the international model systems, they focused on SCENES (Scenarios for European transport) and NEAC models for Europe (EXPEDITE 2002), as well as they pointed out models for specific international corridors (e.g. fixed link projects in Scandinavia, Alpine crossings). Following the traditional multi-step approach, they presented a classification of existing models into an aggregation of four classes: models for production and attraction (including trend and time series, system dynamics, zonal trip rate and input-output models), models for distribution, models for modal split and models for assignment.

Chow et al. (2010) reviewed freight forecasting models and current advances and needs with respect to data and model development. They used California as 
case study throughout their evaluation as a representative region. They extend the National Cooperative Highway Research Program (NCHRP 2008) based on five model classes including Logistics Models and Vehicle Touring ones. As suggested by Fischer et al. (2005), these classes of models could improve the sensitivity of models to the economics of commodities for policy-making and more, as well as they better capture the movements of vehicles for impact assessment.

Finally, De Jong et al. (2013) provide a review of the European literature on freight transport models that operate at the national or international level and have been developed since 2004. They argued that the most important recent improvement in freight modelling was the introduction of logistics decision-making and although we are still far away from solving this issue, they identify some elements which might be the next key developments for practical freight models, such as production, inventory and transport logistics, including their integration with urban freight models (in order to point out the consumption demand (Comi et al. 2012)).

In order to picture a concise framework of the main studies developed for the analysis of international freight demand, starting from the classification proposed by the authors in previous studies (Nuzzolo et al. 2009), the recent and sophisticated systems of models for freight demand estimation can be carried out by the integration of two classes of models:

- macro-economic models, which simulate the level (quantity) and spatial distribution of goods exchanged between different economic zones (leading to origin-destination matrices) by:

- joint models, e.g. macroeconomic (Oum et al. 1990; Bougheas et al. 1999; Zhao, Kockelman 2004; Marzano, Papola 2008);

- partial share models (Wilson 1974; Coto-Millán et al. 2005; Russo, Assumma 2007; Nuzzolo et al. 2010; Bröcker et al. 2011);

- behavioural models that simulate mode and route choice (Winston 1983; Vieira 1992; Nuzzolo, Russo 1997; García-Menéndez et al. 2004; De Jong, Ben-Akiva 2007; Quattrone, Vitetta 2008; Kepaptsoglou et al. 2009; Russo et al. 2009; Rich et al. 2011; Yang et al. 2011).

Within this general modelling framework, this paper proposes a system of models that aims at reducing the complexity of the macro-economic models and allows us a first estimation of import and export freight in terms of quantity, characterised by transport mode, too. For example, this system of models could be used for studying the effects of future strategies on freight transport. Such aggregate import and export models seem to tend to ignore the simultaneous relationship between quantity and price as evidenced by Arize (1986), but the modelling structure can be considered a general framework that allows us to easily include the possible inter-relationships that can modify the production or attraction demand as well as the transport modes they use. In fact, it allows us to estimate a first magnitude of import/export flows using an aggregate modelling system specified within the partial share approach. The modelling system has been calibrated by means of data available from national and international organizations (e.g. Italian Institute of Statistics, EuroStat, World Trade Organisation, and Institute for the International Commerce) and it should be applied for long term import/ export freight forecasts.

Section 1 introduces the structure of the proposed modelling system for import and export flow simulation in quantities. Section 2 describes the dataset used for the specification and calibration, while section 3 reports the calibration results. The final section summarises some conclusions and possible developments of this research.

\section{The Proposed Modelling System}

The proposed modelling system has been developed in order to estimate the import/export quantity freight flows from/to a given country and disaggregated for freight types and transport modes. The modelling structure (Fig. 1) can be considered an extension to all transport modes of the modelling system proposed by the authors for the estimation of international freight transport flows by road (Nuzzolo et al. 2009). The international freight flows are usually analysed through statistical methods such as gravity model (Bougheas et al. 1999) or spatial and temporal interaction models (Garrido 2000; Regan, Garrido 2001; Washington et al. 2010) based on statistical and descriptive analyses of available data. Such analyses present a certain level of approximation in the case in which particular conditions, for example, economic development happens, such as, regression periods. In fact, these types of models analyse singular periods as stochastic elements that modify the following predictions without introducing explanatory factories. Although easy-to-capture variables are used, the proposed modelling system allows to simulate the economic development on the basis of variations defined

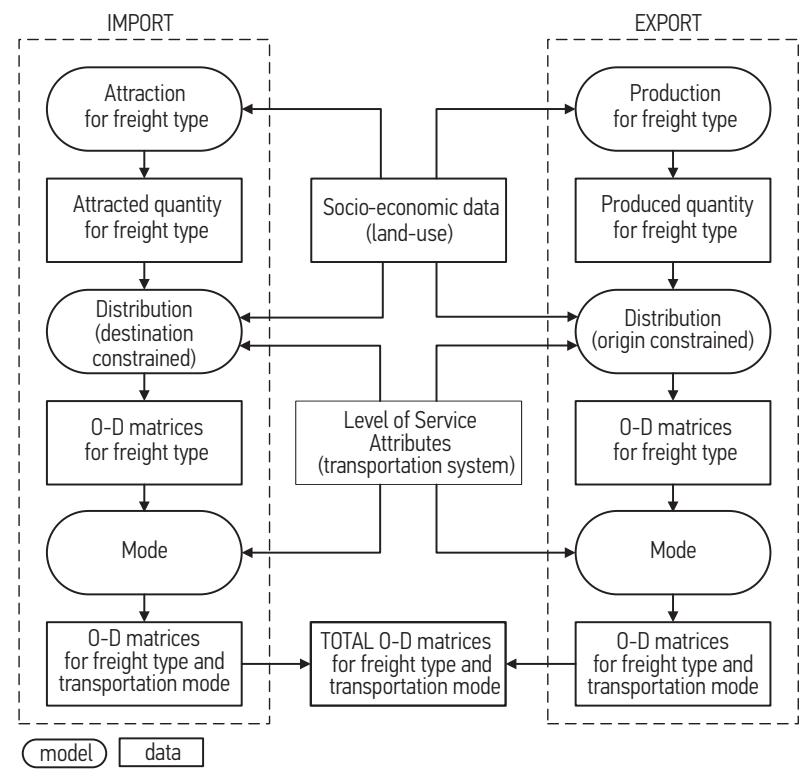

Fig. 1. The proposed modelling system 
on some explanatory macro-economic variables (e.g. variation of GDP or employees). They can be applied to a configuration of the activity and transport system (which is not sensitive to the above particular conditions) to derive estimates of simulated configurations on the evolution of these systems (scenarios) to obtain hypothetical forecasts of future demand.

The proposed modelling system has been specified within the partial share approach aiming at characterising import/export freight flows as:

- origin and destination;

- time period;

- freight type, e.g. perishable goods, non-perishable, and so on;

- transport mode, e.g. road, road-railway transport, road-sea transport, air transport.

Given the inside (with respect to the considered country) traffic zone $x$ and the outside (with respect to the considered country) traffic zone $y$ for which the international freight flows are analysed, the import $(i)$ and export (e) quantity flows of freight type $s$ in the time period $h$ (e.g. year) transported by transport mode $m$ can be expressed as:

$$
\begin{aligned}
& Q_{y x}{ }^{i, s h}[m]=Q_{x}^{i, s h} \cdot p^{i}[y / x s h] \cdot p^{i}[m / y x s h] ; \\
& Q_{x y}{ }^{e, s h}[m]=Q_{x}{ }^{e, s h} \cdot p^{e}[y / x s h] \cdot p^{e}[m / x y s h],
\end{aligned}
$$

where: $Q_{y x}{ }^{i, s h}[m]$ is the average import (i) quantity flow of freight type $s$ in the time period $h$ that reaches the traffic zone $x$ coming from zone $y$ by transport mode $m ; Q_{x y}{ }^{e, s h}[m]$ is the average export (e) quantity flow of freight type $s$ in the time period $h$ that departs from traffic zone $x$ and reaches the zone $y$ by transport mode $m ; Q_{x}{ }^{i, s h}$ is the average import quantity flow of freight type $s$ in the time period $h$ attracted by zone $x$, which can be estimated by an attraction model; $Q_{x}{ }^{e, s h}$ is the average export quantity flow of freight type $s$ in the time period $h$ generated by zone $x$, which can be estimated by a production model; $p^{i}[y / x s h]$ is the probability that the import freight of type $s$ in the time period $h$ attracted by traffic zone $x$ comes from zone $y$, which can be estimated by a distribution model constrained to the destination (i.e. zone $x$ ); $p^{e}[y / x s h]$ is the probability that the export freight of type $s$ in the time period $h$ generated by traffic zone $x$ is destined to zone $y$, which can be estimated by a distribution model constrained to the origin (i.e. zone $x$ ); $p^{i}[m / y x s h]$ is the probability that the import freight of type $s$ in the time period $h$ on the $y x$ pair is transported by mode $m$, which can be estimated by a mode choice model; $p^{e}[m / x y s h]$ is the probability that the export freight of type $s$ in the time period $h$ on the $x y$ pair is transported by mode $m$, which can be estimated by a mode choice model.

Attraction models allow us to estimate freight attracted (imported) by each national traffic zone from foreign zones. Production models allow us to estimate freight produced by each national traffic zone and exported to foreign zones. Distribution models are used to obtain the spatial share of freight flows; they can be differently speci- fied for import and export. Mode choice models allow us to simulate the distribution of freight flows between different transport modes and services. They can be differently specified for import and export, too.

In the following, for simplicity of notation, the class indexes $s$ (freight type) and $h$ (time period) will be omitted unless stated otherwise.

The output of the proposed modelling system can be the input for logistics model developed mainly in the field of operational research (Crainic 2002) for designing the freight network in terms of number and location of Logistics Centers. In fact, the logistics models (BenAkiva, De Jong 2008) allow to determine which flows are covered by direct transports and which transports will use ports, airports, consolidation centres and/or railway terminals.

To test the goodness of the proposed modelling system, some specific models have been specified and calibrated by using Generalized Least Squares (GLS) estimator within the classic theory of statistical inference by aggregate data (Origin-Destination information) on the basis of observed O-D freight flows per mode and freight type. The presented models are the result of several specifications and calibrations based on different combinations of possible attributes. Such attributes have been chosen according to their easy-to-capture possibility based on the best explanatory power in terms of problem representation and reproduction for both transport and socio-economic variables.

As these variables intrinsically represent aggregate data that can be easily found on common Italian and European datasets (e.g. Italian Institute of Statistics and EuroStat), the modelling system is suitable to be used for strategic planning; the use for tactical-operational planning is not recommended as reliable forecasts in this last case require the use of specific variables representing logistics and supply chain aspects, which are not considered here because they are often difficult to estimate at the international scale.

The modelling system has been implemented within a DSS which includes an intuitive Graphic User Interface (GUI) able to manage input data, to create scenarios (including the transport demand and supply components), as well as to support the analysis of simulation results through analytical reports and graphs.

In the following, models with the best statistical performances are reported.

\section{The Dataset}

The study area is the whole Europe divided into traffic zones by considering NUTS (European Nomenclature of Territorial Units for Statistics; EC 2003) at level 1, except for Italy that has been divided into 103 traffic zones at province level as models have been specified for the Italian import/export.

The system of models described in the previous section has been specified and calibrated for the estimation of Italian import/export flows within Europe by using the following data sources: 
- Italian census data, where the socio-economic information is aggregated per economic sectors under ATECO classification used by ISTAT (National Institute of Statistics), which derives from the international NACE (European Classification of Economic Activities) classification;

- Italian Institute for Foreign Trade (ICE) that gives some updated information on Italian international trade in order to support the internationalisation of Italian firms and their consolidation in foreign markets;

- Italian Ministry of Transport, in order to characterise import/export flows for transport mode;

- Eurostat and World Trade Organization (WTO) data, in order to analyse import/export flows and socio-economic information for the European countries. ered:

The following four freight types have been consid-

- perishable and non-dangerous goods, e.g. foodstuffs;

- non-perishable and non dangerous goods, e.g. wood products;

- chemical and petroleum products;

- machinery, transport equipment, manufactured articles and miscellaneous articles.

They have been defined by considering other Italian studies on freight transport demand (Russo 2005; Nuzzolo et al. 2009), the current freight classifications (e.g. Goods Nomenclature for Transport Statistics Revised; NST/R 1967) and the homogeneity with respect to the transport attributes.

Before deepening on model specification and calibration we focused on the analysis of different data available from several sources in order to identify the main features of Italian import/export, for which data are available in both value and quantity. Thus, the $\mathrm{O}-\mathrm{D}$ matrices based on the given zoning in terms of quantity and freight types have been estimated. Tables 2 and 3 report the aggregate results in terms of freight types and transport modes.

Referring to year 2008 that is the year for which consolidated data are available and for which the effects of current financial crisis can be assumed negligible, Table 2 reports the import/export freight type distribution according to the considered classification. Percentages of Table 2 refer to a total amount of 362 million of import tons and about 144 million of export tons transported by all modes. The $58.9 \%$ of the whole amount refers to the import of chemical and petroleum products. In particular, analysing disaggregate data, the $45 \%$ of the import refer to petroleum products, which are mainly transported by sea (64\%). For what concerns the exports flows, about the $70 \%$ of freight concerns non-perishable $(38.1 \%)$ and chemical products $(32.0 \%)$. Referring to the transport mode, about the $41 \%$ of exported freight is moved by road and the $54.2 \%$ by sea.

Analysing the time series of the last ten years (1999-2008) pictured in Fig. 2, it is possible to point out an increase of $27 \%$ and $18 \%$ for import and export, respectively. In particular, the import flow of non-per-
Table 2. Import/export distribution for freight types (2008)

\begin{tabular}{lcc|cc}
\hline & \multicolumn{2}{c|}{$\begin{array}{c}\text { Import } \\
{\left[10^{3} \text { tons/year }\right]}\end{array}$} & \multicolumn{2}{c}{$\begin{array}{c}\text { Export } \\
{\left[10^{3} \text { tons/year }\right]}\end{array}$} \\
\hline Freight types & values & $\%$ & values & $\%$ \\
\hline Perishable & 43102 & $11.9 \%$ & 23246 & $16.2 \%$ \\
\hline Non-perishable & 58605 & $16.2 \%$ & 54890 & $38.1 \%$ \\
\hline Chemical & 213248 & $58.9 \%$ & 45968 & $32.0 \%$ \\
\hline Mechanical & 47003 & $13.0 \%$ & 19648 & $13.7 \%$ \\
\hline Total & 361958 & $100.0 \%$ & 143752 & $100.0 \%$ \\
\hline
\end{tabular}

Source: ICE (2009)

Table 3. Import/Export distribution for transport modes (2008)

\begin{tabular}{lcc|cc}
\hline & \multicolumn{2}{c|}{$\begin{array}{c}\text { Import } \\
{\left[10^{3} \text { tons/year }\right]}\end{array}$} & \multicolumn{2}{c}{$\begin{array}{c}\text { Export } \\
{\left[10^{3} \text { tons/year }\right]}\end{array}$} \\
\hline Transport mode & values & $\%$ & values & $\%$ \\
\hline Road & 59912 & $16.6 \%$ & 58956 & $41.0 \%$ \\
\hline Air & 395 & $0.1 \%$ & 2219 & $1.5 \%$ \\
\hline Railway & 16235 & $4.4 \%$ & 4766 & $3.3 \%$ \\
\hline Sea & 284417 & $78.9 \%$ & 77812 & $54.2 \%$ \\
\hline Total & 361958 & $100.0 \%$ & 143752 & $100.0 \%$ \\
\hline
\end{tabular}

Source: ICE (2009)
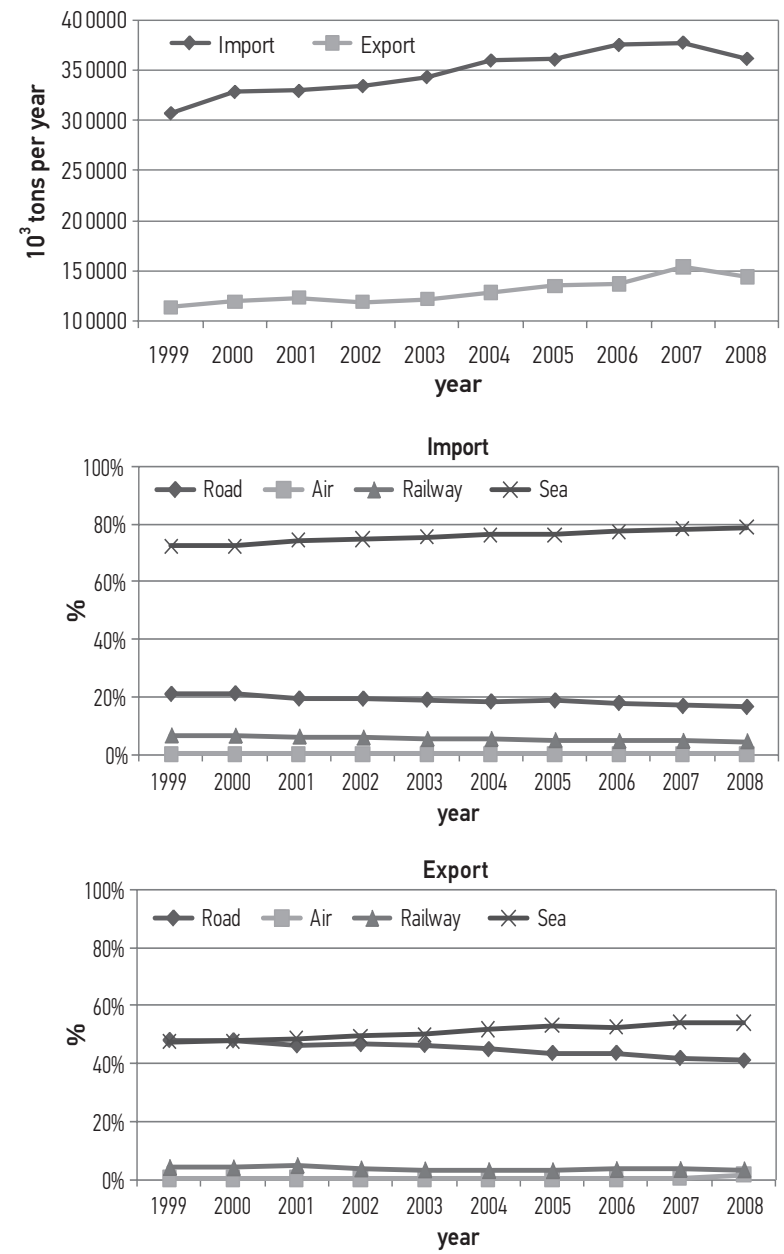

Fig. 2. Import and export trends 
ishable goods increased of about the $45 \%$ with respect to the $11 \%$ of other freight classes. The trend of export flow is quite different. In-depth analysis, here omitted for the reader convenience, shows that non-perishable goods increased of about the 51\%, but perishable and machinery products remain practically constant (only $1 \%$ ).

\section{Specification and Calibration}

In order to estimate the modal O-D matrices in quantities, the system of models described in the Introduction and in Section 1 has been specified and calibrated for Italian import/export flows on the basis of the dataset described in Section 2. Different freight types and transport mode-services for both import and export have been considered. Section 3.1 describes results obtained for the attraction and production models; Section 3.2 reports the features of distribution models, while Section 3.3 describes the specification and calibration of mode choice models.

\subsection{The Attraction and Production Models}

The analysis of available data pointed out that the average quantity of freight attracted (for the import) or produced (for the export) are strictly related to the number of employees of the zone referred to the considered freight (emp) and the average Gross Domestic Product (GDP). Models have been calibrated in order to simulate the Italian import/export freight traffic with respect to the other countries within Europe.

For what concerns the attraction model, the average flow of freight quantity attracted by zone $x, Q_{x}^{i}$, can be estimated by a descriptive model belonging to the category regression class, for which $Q_{x}^{i}$ can be expressed as a function, typically linear, of variables $X_{j x}$ (or their transformations) representative of the destination zone $x$, as:

$$
Q_{x}^{i}=\sum_{j} \beta_{j} X_{j x}+\varepsilon^{i},\left[10^{3} \text { tons / year }\right],
$$

where $\beta_{j}$ are the model coefficients to be estimated and $\varepsilon^{i}$ is the error component.

The reported models were calibrated employing the Generalised Least Squares (GLS) method. First, the freight quantity imported by each traffic zone was obtained from survey data $\hat{Q}_{x}$, and then the parameters $(\beta)$ were estimated solving the following expression:

$$
\min _{\beta} Q=\sum_{x}\left(Q_{x}-\hat{Q}_{x}\right)^{2}
$$

The capability to reproduce the revealed observations was measured by the coefficient of determination $R^{2}\left(R^{2}=1-S S E / S S T\right.$, where SSE is the sum of square errors and SST is the total sum of squares). The parameter estimation was similarly performed for other models.

Table 4 reports values of $\beta_{j}$ parameters calibrated for the four considered freight types, as well as for all freight types together. All parameters are correct in sign and are statistically significant as shown by $t$-student values that are reported in brackets below the estimated parameter value. The capability of models to reproduce the revealed values is shown by values of $R^{2}$ that are similar to those reported in the literature. Results highlight that for all types of freight the number of employees of the given traffic zone (precisely its natural logarithm) is quite significant. The GPD for Chemical and Mechanical products is more relevant than the other freight types. In fact, these freight types represent the main part of the economy of a country whose levels of productivity are better measured by GDP. Some specifications including the number of inhabitants to measure the zone attraction power were also tested, but the calibrations did not give statistical significance for this type of attribute.

In a similar way, we can estimate the export flow. In fact, the production model allows us to estimate the average flow of freight departing from zone $x, Q_{x}^{e}$. In this case, the category regressive model is specified through variables representative of freight type and origin zone $x$, as:

$$
Q_{x}^{e}=\sum_{j} \beta_{j} X_{j x}+\varepsilon^{e},\left[10^{3} \text { tons } / \text { year }\right],
$$

where: $\beta_{j}$ are the model coefficients to be estimated and $\varepsilon^{e}$ is the error component.

Table 5 reports values of $\beta_{j}$ parameters calibrated for the four freight types, as well as for all freight together.

All parameters are correct in sign and are statistically significant as shown by $t$-student values (reported in brackets below the estimated parameter values), while values of $R^{2}$ are similar to those present in the literature for models of this type. The emission power is measured through the number of employees or their function (e.g. natural logarithm) and the parameter for perishable goods is about twice less than that calibrated for nonperishable goods. In the estimation of the production for industrial goods (i.e. chemical and mechanical), the GDP weight is more relevant and its effect is similar to that previously described for the attraction model.

Deepening on the calibration results, it is interesting to compare parameters for import and export. At first, we can see that the attraction and production power of each zone is measured by the number of employees and GDP. In the case of models for all freight types (aggregate models) the weight of import parameters is more than four times that relative to export, which reflects statistics pictured. The import volume of freight is strictly related to GDP more than the number of employees. It confirms that Italy imports a lot of freight in order to satisfy its internal demand. The GPD is highly significant for all freight types and its weight is more significant for industrial products (i.e. chemical and mechanical), as expected.

Finally, Table 6 shows the estimation of the elasticity with respect to GPD of import and export commodity tons. The positive values confirm that the share production increases with the increase of income per capita. Export values are higher than import ones, while the import average value is higher than export one. The export elasticity of single freight types is about three times the import. It demonstrates that increasing the GDP the 
Table 4. Attraction model (import): calibration results in $10^{3}$ tons/year

\begin{tabular}{ccccccc}
\hline \multirow{2}{*}{ Parameters } & \multirow{2}{*}{ Unit } & Aggregate (all freight) & \multicolumn{4}{c}{ Freight type } \\
\cline { 3 - 7 } & & Perishable & Non-perishable & Chemical & Mechanical \\
\hline$\beta_{e m p}$ & $233.65^{*}$ & 0.0135 & 129.6 & 0.436 & 0.201 \\
$(t$-st $)$ & $(5.2)$ & $(7.7)$ & $(5.6)^{*}$ & $(2.6)$ & $(3.7)$ \\
\hline$\beta_{G D P}$ & \multirow{2}{*}{$10^{6} €$} & $0.0837^{* *}$ & $0.0004^{* *}$ & $0.014^{* *}$ & $0.046^{* *}$ & $0.019^{* *}$ \\
$(t$-st $)$ & $(22.2)$ & $(3.8)$ & $(9.5)$ & $(16.7)$ & $(11.7)$ \\
\hline$R^{2}$ & 0.85 & 0.53 & 0.58 & 0.79 & 0.68 \\
\hline
\end{tabular}

Notes: ${ }^{\star}$ parameter value valid for natural logarithm of the correspondent attribute; ${ }^{\star \star}$ parameter value valid for exponential function of the correspondent attribute expressed in $10^{-7} €$.

Table 5. Production model (export): calibration results in $10^{3}$ tons/year

\begin{tabular}{ccccccc}
\hline \multirow{2}{*}{ Parameters } & \multirow{2}{*}{ Unit } & \multirow{2}{*}{ Aggregate (all freight) } & \multicolumn{4}{c}{ Freight type } \\
\cline { 3 - 7 } & & Perishable & Non-perishable & Chemical & Mechanical \\
\hline$\beta_{\text {emp }}$ & & $69.667^{*}$ & $51.057^{*}$ & $96.615^{*}$ & $71.065^{*}$ & $59.001^{*}$ \\
$(t$-st $)$ & $(1.4)$ & $(3.2)$ & $(4.5)$ & $(1.7)$ & $(1.7)$ \\
\hline$\beta_{G D P}$ & \multirow{2}{*}{$10^{6} €$} & $2.75 \cdot 10^{-5}$ & $0.050^{* *}$ & $1.58 \cdot 10^{-6^{* *}}$ & $3.67 \cdot 10^{-6}$ & $6.86 \cdot 10^{-6^{* *}}$ \\
$(t$-st $)$ & $(3.3)$ & $(1.4)$ & $(2.2)$ & $(1.1)$ & $(1.5)$ \\
\hline$R^{2}$ & 0.75 & 0.72 & 0.67 & 0.78 & 0.66 \\
\hline
\end{tabular}

Notes: ${ }^{\star}$ parameter value valid for natural logarithm of the correspondent attribute; ${ }^{\star \star}$ parameter value valid for exponential function of the correspondent attribute expressed in $10^{-7} €$.

Table 6. Elasticity of commodity with respect to GDP of importer and exporter

\begin{tabular}{lccccc}
\hline & $\begin{array}{c}\text { Aggregate } \\
\text { (all freight) }\end{array}$ & $\begin{array}{c}\text { Perish- } \\
\text { able }\end{array}$ & $\begin{array}{c}\text { Non-per- } \\
\text { ishable }\end{array}$ & $\begin{array}{c}\text { Chemi- } \\
\text { cal }\end{array}$ & $\begin{array}{c}\text { Mechan- } \\
\text { ical }\end{array}$ \\
\hline Import & 1.26 & 1.07 & 1.26 & 0.27 & 0.25 \\
\hline Export & 0.95 & 3.57 & 4.33 & 0.95 & 0.45 \\
\hline
\end{tabular}

new demand of freight is mainly destined to foreign markets. As expected, the elasticity related to consumer demand (i.e. perishable and non-perishable goods) has higher values than for other freight types. The values for chemical and mechanical products are smaller than the others, meaning that demand ratios change less than production ones.

\subsection{The Distribution Models}

Distribution models can be interpreted and specified following either a behavioural or a descriptive approach with different specifications and interpretations of the considered attributes (Cascetta 2009). According to the behavioural interpretation, the distribution model simulates the choice of a destination among possible alternatives. It should be noted that typically the chosen alternative for carrying out an activity is not a traffic zone but one or more elementary alternatives (such as a firm, a general market, etc.) located within the zone. The traffic zone is therefore a compound alternative made of an aggregation of elementary alternatives.

Variables considered into the distribution model can be divided into two groups: variables representing the activity system (which measure the generation/emission/production or attraction power of a given zone for freight type $s$, e.g. employees of freight type $s$ ) and variables representing cost or separation attributes (which measure the generalized travel cost for transporting freight type $s$ on the O-D pair).

Referring to import, the distribution model is destination constrained; it allows us to estimate the probability of departing from the foreign zone $y$ for freight arriving to national zone $x$. In the framework of the Random Utility Theory (Ben-Akiva, Lerman 1985), these probabilities can be expressed by a logit model as:

$$
\begin{aligned}
& p^{i}[y / x]=\exp \left(V_{y}^{i} / \theta_{y}^{i}\right) / \sum_{y^{\prime} \in I_{x}^{i}} \exp \left(V_{y^{\prime}}^{i} / \theta_{y}^{i}\right) \\
& \forall y^{\prime} \neq y, y, y^{\prime} \in I_{x}^{i},
\end{aligned}
$$

where: $V_{y}^{i}$ is the systematic utility of the foreign origin zone $y$, that can be expressed as a linear combination of attributes, $X_{j y} ; I_{x}^{i}$ is the set of possible foreign origin zones from which import freight can arrive to a given national zone $x ; \theta_{y}^{i}$ is the parameter of the Gumbel random variable.

The systematic utility $V_{y}^{i}$ has been expressed as linear combination of the attributes of possible foreign origins in relation to the national zone of destination:

$V_{y}^{i}=\sum_{j} \beta_{j}^{i} \cdot X_{j y}=\beta_{k m}^{i} \cdot K M_{y x}+\beta_{\mathrm{GDP}}^{i} \cdot G P D_{y}+\beta_{e m p}^{i} \cdot E M P_{y}$, where: $K M_{y x}$ is the distance between $y$ and $x$ zones, expressed in $\mathrm{km}$; $G P D_{y}$ is the GDP of the foreign origin zone $y$, expressed in $€ ; E M P_{y}$ is the number of employees at the foreign origin zone $y ; \beta_{j}^{i}$ are the model parameters to be estimated.

As regards the export, using the same RUM (Random Utility Model) framework described for import, the probability of reaching the foreign destination zone $y$ for freight departing from a given national zone $x$ can be 
estimated by an origin constrained distribution model:

$$
\begin{aligned}
& p^{e}[y / x]=\exp \left(V_{y}^{e} / \theta_{y}^{e}\right) / \sum_{y^{\prime} \in I_{x}^{e}} \exp \left(V_{y^{\prime}}^{e} / \theta_{y}^{e}\right) \\
& \forall y^{\prime} \neq y ; y, y^{\prime} \in I_{x}^{e},
\end{aligned}
$$

where: $V_{y}^{e}$ is the systematic utility of the foreign destination zone $y$, that can be expressed as a linear combination of attributes $X_{j y} ; I_{x}^{e}$ is the set of possible foreign destination zones to which export freight can be destined from the given national zone $x ; \theta_{y}^{e}$ is the parameter of the Gumbel random variable.

The systematic utility $V_{y}^{e}$ has been expressed as linear combination of the attributes of possible foreign destinations as follows:

$$
\begin{aligned}
& V_{y}^{e}=\sum_{j} \beta_{j}^{e} \cdot X_{j x}=\beta_{k m}^{e} \cdot K M_{x y}+\beta_{\mathrm{GDP}}^{e} \cdot G P D_{y}+ \\
& \beta_{\text {emp }}^{e} \cdot E M P_{y}+\beta_{p o p}^{e} \cdot P O P_{y}+\beta_{d i s t}^{e} \cdot D I S T_{x y},
\end{aligned}
$$

where: $K M_{y x}$ is the distance between $x$ and $y$ zones, expressed in $\mathrm{km} ; G P D_{y}$ is the GDP of the foreign destination zone $y$, expressed in $€ E M P$ is the number of employees at the foreign destination zone $y ; P O P_{y}$ is the density of inhabitants at the foreign zone $y$, expressed in inhabitants per $\mathrm{km}^{2}$; DIST $x y$ is a dummy variable equal to 1 if the distance between the two zones $x$ and $y$ is less than $500 \mathrm{~km}, 0$ otherwise; $\beta_{j}^{e}$ are the model parameters to be estimated.

Tables 7 and 8 report the set of parameters calibrated for both import and export by an aggregated calibration method (Generalised Least Squares).

$\mathrm{On}$ the basis of available data, the quantity $\mathrm{O}-\mathrm{D}$ flows $\left(\hat{Q}_{x y}\right)$ were obtained. Then, the parameters $(\beta)$ were estimated by solving the following expression:

$$
\min _{\beta} Q=\sum_{y x \text { or } x y}\left(Q_{y x \text { or } x y}-\hat{Q}_{y x \text { or } x y}\right)^{2},
$$

where: $Q_{y x \text { or } x y}\left(=Q_{x} \cdot p[y / x s h]\right)$ is the simulated quantity $\mathrm{O}-\mathrm{D}$ flow.
The coefficient of determination $R^{2}$ has been used in order to verify the goodness of fitting. Both for chemical and mechanical classes the number of employees has not been statistically significant, but for export a dummy variable (DIST) has been included in order to characterise the exchanges with close countries. Its results were significant. In fact, these types of freight are mainly exported to close countries such as France and Germany. It is important to note the presence and the relative signs of inhabitant density attribute within the systematic functions of destination zone. It confirms that the Italian export is mainly characterised by final products destined to satisfy the end-consumer demand. The highest value is relative to perishable goods. Finally, we can note that the import flows can be easy characterised by GDP.

\subsection{The Mode Choice Models}

Mode choice models simulate the probability $p[\mathrm{~m} / \mathrm{od}]$ of using transport mode-service $m$ moving freight types $s$ in time period $h$ from origin zone $o$ to destination zone $d$. Mode choice is a typical example of a travel choice that can be modified for different trips in which performance or level-of-service attributes have considerable influence.

The identification of relevant alternatives (the choice set) depends on the transport system under study. For modal choice models, the definition of the choice set of each decision-maker is particularly important. In fact, not all transport modes are available for all trips, due to unavailability of the road-sea combined transport for users operating very far from ports or because it is not perceived as an alternative (e.g. combined transport services are not considered for short trips). In our case, the following transport service-modes have been considered: road, road-railway, road-sea and air.

Level-of-service or performance attributes define the systematic utility functions of mode choice models. They

\begin{tabular}{|c|c|c|c|c|c|c|}
\hline \multirow{2}{*}{ Parameters } & \multirow{2}{*}{ Unit } & \multirow{2}{*}{ Aggregate (all freight) } & \multicolumn{4}{|c|}{ Freight type } \\
\hline & & & Perishable & Non-perishable & Chemical & Mechanical \\
\hline$\beta_{e m p}$ & & 0.001 & 0.392 & 0.144 & & \\
\hline$\beta_{G D P}$ & $10^{6} €$ & 0.727 & 2.846 & 0.778 & 0.099 & 0.620 \\
\hline$\beta_{k m}$ & $\mathrm{~km}$ & -0.234 & -2.883 & -0.195 & -1.651 & -0.263 \\
\hline$\beta_{p o p}$ & $\mathrm{inh} / \mathrm{km}^{2}$ & 0.002 & 2.666 & 0.111 & 0.012 & 0.045 \\
\hline $\mathrm{B}_{D I S T}$ & $0 / 1$ & & & & 1.868 & 0.366 \\
\hline$R^{2}$ & & 0.45 & 0.51 & 0.42 & 0.38 & 0.46 \\
\hline
\end{tabular}

Table 7. Distribution model for import: calibration results

\begin{tabular}{ccccccc}
\hline \multirow{2}{*}{ Parameters } & \multirow{2}{*}{ Unit } & Aggregate (all freight) & \multicolumn{5}{c}{ Freight type } \\
\cline { 3 - 7 } & & 0.024 & Perishable & Non-perishable & Chemical & Mechanical \\
\hline$\beta_{e m p}$ & & 1.203 & 1.413 & 0.855 & 1.520 & 0.911 \\
\hline$\beta_{G D P}$ & $10^{6} €$ & 0.167 & 0.543 & -2.813 & \\
\hline$\beta_{k m}$ & $\mathrm{~km}$ & -1.076 & -2.473 & & 0.57 & 0.23 \\
\hline$R^{2}$ & & 0.61 & 0.65 & 0.30 & 0.57 &
\end{tabular}

Table 8. Distribution model for export: calibration results 
describe the service features offered by the specific service-mode. Examples of such attributes are travel time (possibly decomposed into access/egress time, waiting time, on-board time, and so on), monetary cost, service regularity, number of transfers. The specified and calibrated models are based on the Random Utility Theory (Ben-Akiva, Lerman 1985; Cascetta 2009). These models are aggregate models because they are based on data and attributes corresponding to aggregate freight flows between different zones with available transport modes. They have a functional form that belongs to the Logit family (i.e. Multinomial Logit type). Choice alternatives correspond to the available transport modes for a given consignment considering the different services (e.g. combined road-railway transport). Model specification is the same for both import and export, while calibration results are different. The probability $p[\mathrm{~m} / \mathrm{od}]$ has been expressed as:

$$
\begin{aligned}
& p[m / o d]=\exp \left(V_{m}^{o d} / \theta_{m}\right) / \sum_{m^{\prime} \in I_{o d}} \exp \left(V_{m^{\prime}}^{o d} / \theta_{m^{\prime}}\right) \\
& \forall m^{\prime} \neq m ; m, m^{\prime} \in I_{o d},
\end{aligned}
$$

where: $V_{m}^{o d}$ is the systematic utility of transport mode- service $m$, that can be expressed as a linear combination of attributes $X_{j m}^{o d} ; I_{o d}$ is the set of possible transport mode-services available on the od pair; $\theta_{m}$ is the parameter of the Gumbel random variable.

The systematic utility $V_{m}^{o d}$ has been expressed as linear combination of level-of-service attributes, as follows:

$$
\begin{aligned}
& V_{m}^{o d}=\sum_{j} \beta_{j m} \cdot X_{j m}^{o d}= \\
& \beta_{c, m} \cdot C_{m}^{o d}+\beta_{t, m} \cdot T_{m}^{o d}+\beta_{m} \cdot A S A_{m},
\end{aligned}
$$

where: $C_{m}^{o d}$ is the travel cost for the transport mode-service $m$ on the od pair, expressed in $€$; $T_{m}^{o d}$ is the travel time for the transport mode-service $m$ on the od pair, expressed in hours; $A S A_{m}$ is the Alternative Specific Attribute (ASA), which is a dummy variable equal to 1 for the considered transport mode-service $m ; \beta_{j, m}$ are the model parameters to be estimated.

Two different classes of models have been specified and calibrated: one for import and one for export. Tables 9 and 10 report the obtained results of the aggregate calibration for the considered freight types.

Table 9. Mode choice model for import calibration results

\begin{tabular}{cccccccc}
\hline \multirow{2}{*}{ Parameter } & \multirow{2}{*}{ Transp. mode } & Unit & \multirow{2}{*}{ Aggregate (all freight) } & \multicolumn{3}{c}{ Freight type } \\
\cline { 6 - 8 } & & & & Perishable & Non-perishable & Chemical & Mechanical \\
\hline$\beta_{c}$ & road & $€$ & -0.0113 & -0.0147 & & -0.0062 \\
\hline$\beta_{t}$ & road & $\mathrm{h}$ & -0.6064 & -6.6232 & -0.1928 & -0.0185 & -1.3221 \\
\hline$\beta_{c}$ & road-railway & $€$ & -0.0353 & -0.0204 & & -0.0145 \\
\hline$\beta_{t}$ & road-railway & $\mathrm{h}$ & -1.8379 & -6.3118 & -0.3133 & -0.3658 & -2.2018 \\
\hline$\beta_{c}$ & air & $€$ & -0.0371 & -0.0033 & & -0.0461 \\
\hline$\beta_{t}$ & air & $\mathrm{h}$ & -2.3030 & -0.1381 & -0.8265 & -0.6646 & -2.6642 \\
\hline$\beta_{c}$ & road-sea & $€$ & -0.0353 & -0.1105 & & -0.0488 \\
\hline$\beta_{t}$ & road-sea & $\mathrm{h}$ & -1.8379 & -2.3794 & -1.7233 & -0.4491 & -1.3650 \\
\hline$A S A_{r r}$ & road-railway & $0 / 1$ & 0.0006 & -0.0002 & -0.0002 & -0.2347 & -0.0001 \\
\hline$A S A_{a}$ & air & $0 / 1$ & -0.0001 & -0.0004 & -0.0001 & -0.7930 & -0.0002 \\
\hline$A S A_{r s}$ & road-sea & $0 / 1$ & -0.0371 & -0.0051 & -0.0002 & 0.0574 & -0.0001 \\
\hline$R^{2}$ & & & 0.95 & 0.96 & 0.93 & 0.94 & 0.92 \\
\hline
\end{tabular}

Table 10. Mode choice model for export calibration results

\begin{tabular}{cccccccc}
\hline \multirow{2}{*}{ Parameter } & \multirow{2}{*}{ Transp. mode } & \multirow{2}{*}{ Unit } & Aggregate (all freight) & \multicolumn{4}{c}{ Freight type } \\
\cline { 5 - 8 } & & & & Perishable & Non-perishable & Chemical & Mechanical \\
\hline$\beta_{c}$ & road & $€$ & -0.0007 & -0.0031 & -0.0011 & -0.0008 & -0.0010 \\
\hline$\beta_{t}$ & road & $\mathrm{h}$ & -0.0340 & -0.1500 & -0.0525 & -0.0395 & -0.0520 \\
\hline$\beta_{c}$ & road-railway & $€$ & -0.0020 & -0.0157 & -0.0019 & -0.0022 & -0.0006 \\
\hline$\beta_{t}$ & road-railway & $\mathrm{h}$ & -0.0240 & -0.1860 & -0.0358 & -0.0541 & -0.0081 \\
\hline$\beta_{c}$ & air & $€$ & -0.0074 & -0.0054 & -0.0052 & -0.0041 & -0.0051 \\
\hline$\beta_{t}$ & air & $\mathrm{h}$ & -0.4884 & -0.4020 & -0.4787 & -0.3366 & -0.4339 \\
\hline$\beta_{c}$ & road-sea & $€$ & -0.0002 & -0.0042 & -0.0004 & -0.0004 & -0.0002 \\
\hline$\beta_{t}$ & road-sea & $\mathrm{h}$ & -0.0020 & -0.0060 & -0.0012 & -0.0037 & -0.0023 \\
\hline$A S A_{r r}$ & road-railway & $0 / 1$ & -0.4400 & -0.1273 & -1.2180 & -1.3203 & -1.1460 \\
\hline$A S A_{a}$ & air & $0 / 1$ & 8.3920 & -0.0032 & -0.0003 & -0.0019 & -6.0910 \\
\hline$A S A_{r s}$ & road-sea & $0 / 1$ & 0.4230 & 3.6645 & -1.7530 & -0.0004 & 0.1360 \\
\hline$R^{2}$ & & & 0.91 & 0.92 & 0.92 & 0.86 & 0.83 \\
\hline
\end{tabular}


As regards size dimension that could influence the choice of transport mode, it is possible to consider that choice is made with a consignment-type approach without considering the trade-off between shipment quantity and frequency. In order to define the level-of-service for each identified mode, a general procedure based on the transport network modelling has been carried out. Referring to the road network, travel time ( $\left.T_{m}^{o d}\right)$ has been calculated as the sum of the on-road travel time and stop time (detailed information can be found in Nuzzolo et al. 2009). For combined and air transports, the travel times have been obtained by statistical models that relate travel times (given by official timetables) and distances on the mode-service network. The handling times at origin and destination terminals as well as the access and egress travel times by road have been included.

The same approach has been used for travel costs. For combined transport, travel costs have been estimated by statistical models that give fares according to the travelled distance. The access-egress and handling costs have been also included. The obtained calibration results gave satisfying results and high stability (i.e. significant parameter for cost with the expected negative sign). For Non-perishable and Chemical products in import, the cost parameters are not statistically significant and are not included in the final calibration reported in Table 9. Furthermore, it is important to note the VOT (Value-ofTime) values (both for import and export) reported in Table 11. Similar results have been obtained for road and air transports for both import and export flows. Very different values are relative to road-railway and road-sea. The low values of these variables for export confirm that, in Italy, the combined transports are only used to move

Table 11. Value-of-time [€/h]

\begin{tabular}{lcc}
\hline \multirow{2}{*}{ Transport mode } & \multicolumn{2}{c}{ Value-of-Time $[€ / \mathrm{h}]$} \\
\cline { 2 - 3 } & Import & Export \\
\hline road & 53.58 & 48.85 \\
\hline road-railway & 52.07 & 15.94 \\
\hline air & 62.09 & 65.89 \\
\hline road-sea & 52.07 & 11.71 \\
\hline
\end{tabular}

low value goods, while road or air transport modes are preferred to move high value freight (e.g. perishable goods).

In order to test the sensitivity of the model to the travel cost, Table 12 gives all the aggregate elasticities computed with respect to tonnes when travel costs are increased of $5 \%$. The values of elasticity are also disaggregated for freight types and transport modes. Most of these elasticity values have the same magnitude as those we can find in the literature (Beuthe et al. 2001; Agnolucci, Bonilla 2009; De Jong et al. 2010). The aggregate estimates indicate that road transport tonnage is inelastic, while rail and sea aggregate export demand is elastic but less than import ones. The commodity elasticity exhibits more dispersion. Referring to import flows, the perishable goods demand is more elastic than mechanical ones. In particular, the highest values have been found for the road-sea transport, as expected for its great competitivity. The smallest values refer to air transport that is interested by a small share market. For what concerns the export flows, the highest values refer to air transport, which is very competitive for this market. The opposite comments refer to road-sea transport. In fact, this type of transport is characterised by an inelastic demand although its market share in 2008 is more than $50.4 \%$.

\section{Conclusions}

This paper presented a modelling system for the estimation of international (import/export) freight flows. It uses a partial share approach to simulate production, attraction, distribution, and mode choice for the estimation of O-D matrices.

The modelling system was specified through easyto-capture variables (especially for its forecasting use) represented by level-of-service attributes and aggregate socio-economic variables, such as, GDP and number of employees.

Besides the specification of the modelling system, the calibration to the Italian case study on the basis of the latest panel of available data allowed us to set up an easy-to-apply system of models suitable for strategic planning. It can be used for an initial estimation of the

Table 12. Direct elasticity of commodity with respect to travel cost increasing $(+5 \%)$

\begin{tabular}{|c|c|c|c|c|c|}
\hline \multirow{2}{*}{ Transport mode } & \multirow{2}{*}{ Aggregate (all freight) } & \multicolumn{4}{|c|}{ Freight type } \\
\hline & & Perishable & Non-perishable & Chemical & Mechanical \\
\hline \multicolumn{6}{|c|}{ Import } \\
\hline road & -0.02 & -0.10 & & & -0.02 \\
\hline road-railway & -2.71 & -0.55 & & & -1.66 \\
\hline air & -0.02 & -0.01 & & & -0.01 \\
\hline road-sea & -2.13 & -2.57 & & & -1.22 \\
\hline \multicolumn{6}{|c|}{ Export } \\
\hline road & -0.28 & -0.03 & -0.27 & -0.20 & -0.47 \\
\hline road-railway & -0.52 & -2.50 & -0.73 & -0.98 & -0.14 \\
\hline air & -2.77 & -2.80 & -2.67 & -3.07 & -2.52 \\
\hline road-sea & -0.03 & -0.02 & -0.01 & -0.04 & -0.02 \\
\hline
\end{tabular}


production and attraction potentials of import/export of a given zone by considering different freight types (perishable, non-perishable, chemical and machinery goods) and to focus on the main country macro-economic variables that could explain these types of flows.

Regarding the calibration, results show that all obtained parameters are statistically significant in both expected signs and validation statistics. From the analysis of import, the GDP emerges in the definition of spatial distribution shares for industrial goods in both import and export, even if the influence on import is higher than export flows.

This paper also presented a complete set of direct elasticities with respect to GDP, as well as to travel cost for different mode-services and freight types. Moreover, separate elasticities were estimated for import and export markets. A wide range of estimates from one group of commodities to another seem to characterise this macro-economic approach. Some values could be affected by the lack of disaggregate information related to development of an extensive network that could be extended in order to investigate the stability of presented values.

This system of models can be successfully used for the estimation of import/export freight flows in the initial assessment of future scenarios, as well as to calculate the import/export potentialities of a given zone such as the generic Italian province of the calibration phase.

Further developments of this research mainly regard two topics: the investigation and the definition of specific models in order to simulate the transformation/ conversion from quantity to vehicle (e.g. truck, train, ship), and the possibility to extend the proposed modelling system to include a model for simulating the choice of Logistic Centres where some activities (e.g. groupage/degroupage, packing) are carried out. In fact, the investigation of supply chain influence on the choice of the used transport mode can be considered a first step for the extension of the proposed system of models to tactical-operative planning.

Finally, this modelling system is suitable to be integrated with models developed to simulate the national freight transport demand in order to obtain an useful tool for the assessment of different national scenarios taking into account endogenously the influence of import and export flows.

\section{Acknowledgements}

Authors would like to thank Filippo Persichini and Giorgio Gardusi for their support in the analysis of the dataset and in the definition of Origin-Destination matrices.

\section{References}

Abdelwahab, W. M.; Sargious, M. A. 1991. A simultaneous decision-making approach to model the demand for freight transportation, Canadian Journal of Civil Engineering 18(3): 515-520. http://dx.doi.org/10.1139/191-062

Agnolucci, P.; Bonilla, D. 2009. UK freight demand: elasticities and decoupling, Journal of Transport Economics and Policy 43(3): 317-344.
Arize, A. 1986. The supply and demand for imports and exports in a simultaneous model, Pakistan Economic and Social Review 24(2): 57-76.

Ben-Akiva, M.; Lerman, S. R. 1985. Discrete Choice Analysis: Theory and Application to Travel Demand. The MIT Press. $384 \mathrm{p}$.

Ben-Akiva, M.; Bolduc, D.; Park, J. Q. 2008. Discrete choice analysis of shippers' preferences, in M. Ben-Akiva, H. Meersman, E. Van de Voorde (Eds.). Recent Developments in Transport Modelling: Lessons for the Freight Sector, $135-156$.

Ben-Akiva, M.; De Jong, G. 2008. The aggregate-disaggregateaggregate (ADA) freight model system, in M. Ben-Akiva, H. Meersman, E. Van de Voorde (Eds.). Recent Developments in Transport Modelling: Lessons for the Freight Sector, 117-134.

Beuthe, M.; Jourquin, B.; Geerts, J.-F.; Ha, C. K. N. 2001. Freight transportation demand elasticities: a geographic multimodal transportation network analysis, Transportation Research Part E: Logistics and Transportation Review 37(4): 253-266. http://dx.doi.org/10.1016/S1366-5545(00)00022-3

Bougheas, S.; Demetriades, P. O.; Morgenroth, E. L. 1999. Infrastructure, transport costs and trade, Journal of International Economics 47(1): 169-189. http://dx.doi.org/10.1016/S0022-1996(98)00008-7

Bröcker, J.; Korzhenevych, A.; Riekhof, M. C. 2011. Predicting freight flows in a globalising world, Research in Transportation Economics 31(1): 37-44. http://dx.doi.org/10.1016/j.retrec.2010.11.006

Cascetta, E. 2009. Transportation Systems Analysis: Models and Applications. 2nd edition. Springer. 760 p.

Chow, J. Y. J.; Yang, C. H.; Regan, A. C. 2010. State-of-the art of freight forecast modeling: lessons learned and the road ahead, Transportation 37(6): 1011-1030. http://dx.doi.org/10.1007/s11116-010-9281-1

Comi, A.; Site, P. D.; Filippi, F.; Nuzzolo, A. 2012. Urban freight transport demand modelling: a state of the art, European Transport $\backslash$ Trasporti Europei (51), Paper No 7. Available from Internet: http://www.istiee.org/te

Coto-Millán, P.; Baños-Pino, J.; Castro, J. V. 2005. Determinants of the demand for maritime imports and exports, Transportation Research Part E: Logistics and Transportation Review 41(4): 357-372. http://dx.doi.org/10.1016/j.tre.2004.05.002

Crainic, T. G. 2002. Long haul freight transportation, in R. W. Hall (Ed.). Handbook of Transportation Science, 451516. http://dx.doi.org/10.1007/0-306-48058-1_13

De Jong, G.; Schroten, A.; Van Essen, H.; Otten, M.; Bucci, P. 2010. Price Sensitivity of European Road Freight Transport Towards a Better Understanding of Existing Results: a Report for Transport \& Environment. Report 9012-1. CE Delft. The Netherlands. 139 p. Available from Internet: http://www.ce.nl/ publicatie/price_sensitivity_of_road_freight_transport_towards_a_better_understanding_of_existing_results/1130

De Jong, G.; Ben-Akiva, M. 2007. A micro-simulation model of shipment size and transport chain choice, Transportation Research Part B: Methodological 41(9): 950-965. http://dx.doi.org/10.1016/j.trb.2007.05.002

De Jong, G.; Gunn, H.; Walker, W. 2004. National and international freight transport models: an overview and ideas for future development, Transport Reviews 24(1): 103-124. http://dx.doi.org/10.1080/0144164032000080494

De Jong, G.; Vierth, I.; Tavasszy, L.; Ben-Akiva, M. 2013. Recent developments in national and international freight transport models within Europe, Transportation 40(2): 
347-371. http://dx.doi.org/10.1007/s11116-012-9422-9

EC. 2003. Regulation (EC) No 1059/2003 of the European Parliament and of the Council of 26 May 2003 on the Establishment of a Common Classification of Territorial Units for Statistics (NUTS). Available from Internet: http://eur-lex. europa.eu/LexUriServ/LexUriServ.do?uri=OJ:L:2003:154:0 001:0001:EN:PDF

EXPEDITE. 2002. Expert-System Based Predictions of Demand for Internal Transport in Europe. Final Publishable Report. Project funded by the European Community under the 'Competitive and Sustainable Growth' Programme, Brussels, EU.

Fischer, M. J.; Outwater, M. L.; Cheng, L. L.; Ahanotu, D. N.; Calix, R. 2005. Innovative framework for modeling freight transportation in Los Angeles County, California, Transportation Research Record 1906: 105-112. http://dx.doi.org/10.3141/1906-13

García-Menéndez, L.; Martínez-Zarzoso, I.; De Miguel, D. P. 2004. Determinants of mode choice between road and shipping for freight transport: evidence for four Spanish exporting sectors, Journal of Transport Economics and Policy 38(3): 447-466.

Garrido, R. A. 2000. Spatial interaction between the truck flows through the Mexico-Texas border, Transportation Research Part A: Policy and Practice 34(1): 23-33. http://dx.doi.org/10.1016/S0965-8564(98)00062-7

ICE. 2009. L'Italia nell'economia internazionale. Rapporto ICE 2008-2009. Italian Institute for Foreign Trade, Rome, Italy (in Italian).

ICE. 2012. L'Italia nelleconomia internazionale. Rapporto ICE 2011-2012. Italian Institute for Foreign Trade, Rome, Italy. (in Italian).

Kepaptsoglou, K.; Tsamboulas, D.; Karlaftis, M. G.; Marzano, V. 2009. Free trade agreement effects in the Mediterranean region: an analytic approach based on sure gravity model, Transportation Research Record 2097: 88-96. http://dx.doi.org/10.3141/2097-11

Marzano, V.; Papola, A. 2008. A multi-regional input-output model for the appraisal of transport investments in Europe, in Proceedings of the European Transport Conference 2008, 6-8 October 2008, Noordwijkerhout, The Netherlands. 12 p. Available from Internet: http://abstracts.aetransport. org/paper/index/id/2901/confid/14

McFadden, D.; Winston, C.; Boersch-Supan, A. 1986. Joint estimation of freight transportation decisions under nonrandom sampling, in A. Daugherty (Ed.). Analytical Studies in Transport Economics, 137-157.

NCHRP. 2008. Forecasting Statewide Freight Toolkits. NCHRP Report 606. Transportation Research Board, Washington, D.C., U.S.A. 169 p. Available from Internet: http://onlinepubs.trb.org/onlinepubs/nchrp/nchrp_rpt_606.pdf

NST/R. 1967. Standard Goods Classification for Transport Statistics/Revised. Eurostat, Brussels.

Nuzzolo, A.; Russo, F. 1997. Modal split at international level: a system of models for Italian-based freight, in Proceedings of the European Transport Conference 1997, 1-5 September 1997, Uxbridge, United Kingdom, 43-54. Available from Internet: http://abstracts.aetransport.org/paper/index/ $\mathrm{id} / 486 /$ confid $/ 3$

Nuzzolo, A.; Comi, A.; Coppola, P. 2010. Modelli di distribuzione spaziale della domanda feeder nei porti container hub, in F. Russo (Ed.). Scenari di riferimento per i porti container italiani nel sistema euro-mediterraneo. Applicazioni di modelli e metodi per la previsione della domanda e per la va- lutazione dell'offerta. Franco Angeli, Milan, Italy (in Italian). Nuzzolo, A.; Coppola, P.; Comi, A. 2013. Freight transport modeling: review and future challenges, International Journal of Transport Economics 40(2): 151-181.

Nuzzolo, A.; Crisalli, U.; Comi, A. 2009. A demand model for international freight transport by road, European Transport Research Review 1(1): 23-33.

http://dx.doi.org/10.1007/s12544-008-0003-0

Oum, T. H.; Waters, W. G.; Yong, J. S. 1990. A Survey of Recent Estimates of Price Elasticities of Demand for Transport. Policy, Planning and Research Department working paper. Report Number: WPS359. 61 p.

Quattrone, A.; Vitetta, A. 2008. RUM and non-RUM path choice modelling for national freight transport, in Proceedings of the European Transport Conference 2008, 6-8 October 2008, Noordwijkerhout, The Netherlands. 20 p. Available from Internet: http://abstracts.aetransport.org/ paper/index/id/2844/confid/14

Regan, A. C.; Garrido, R. A. 2001. Modeling freight demand and shipper behaviour: state of the art, future directions, in D. Hensher (Ed.). Travel Behaviour Research: The Leading Edge, 185-218.

Rich, J.; Kveiborg, O.; Hansen, C. O. 2011. On structural inelasticity of modal substitution in freight transport, Journal of Transport Geography 19(1): 134-146. http://dx.doi.org/10.1016/j.jtrangeo.2009.09.012

Russo, F. 2005. Sistemi di trasporto merci - approcci quantitativi per il supporto alle decisioni di pianificazione strategica tattica ed operativa a scala nazionale. Franco Angeli, Milan, Italy (in Italian).

Russo, F.; Assumma, V. 2007. An aggregated system of transport models for the Mediterranean free trade zone, in Proceedings of the 11th World Conference on Transport Research Conference, 24-28 June 2007, Berkeley, USA. 20 p. (CD).

Russo, F.; Vitetta, A.; Comi, A. 2009. Estimation of target time distribution for agri-food products by road transport, in N. H. M. Wilson, A. Nuzzolo (Eds.). Schedule-Based Modeling of Transportation Networks, Springer Science + Business Media, 267-283.

http://dx.doi.org/10.1007/978-0-387-84812-9_14

Thill, J.-C.; Lim, H. 2010. Intermodal containerized shipping in foreign trade and regional accessibility advantages, Journal of Transport Geography 18(4): 530-547. http://dx.doi.org/10.1016/j.jtrangeo.2010.03.010

Vieira, L. F. M 1992. The Value of Service in Freight Transportation: PhD Thesis, Massachusetts Institute of Technology. 227 p. Available from Internet: http://dspace.mit.edu/handle/1721.1/13201

Washington, S. P.; Karlaftis, M. G.; Mannering, F. L. 2010. Statistical and Econometric Methods for Transportation Data Analysis. 2nd edition. Chapman and Hall/CRC. 544 p.

Wilson, A. G. 1974. Urban and Regional Models in Geography and Planning. John Wiley \& Sons Inc. $432 \mathrm{p}$.

Winston, C. 1983. The demand for freight transportation: models and applications, Transportation Research Part A: General 17(6): 419-427. http://dx.doi.org/10.1016/0191-2607(83)90162-0

Yang, X.; Low, J. M. W.; Tang, L. C. 2011. Analysis of intermodal freight from China to Indian Ocean: a goal programming approach, Journal of Transport Geography 19(4): 515-527. http://dx.doi.org/10.1016/j.jtrangeo.2010.05.007

Zhao, Y.; Kockelman, K. M. 2004. The random-utility-based multiregional input-output model: solution existence and uniqueness, Transportation Research Part B: Methodological 38(9): 789-807. http://dx.doi.org/10.1016/j.trb.2003.10.005 